\title{
MODELLING PROCUREMENT PROCESSES BY UML DIAGRAMS
}

\author{
Martin Stransky \\ Czech Technical University in Prague, Czech Republic \\ martin.stransky@fsv.cvut.cz
}

\begin{abstract}
Ongoing digital transformation of the construction industry offers all project stakeholders new opportunities and possibilities for how to improve their business processes. Many research articles, construction, and software companies focus on digitizing designing and building processes with the use of BIM models. However, only a few research articles, construction and software companies provide information on how to digitize the procurement processes within the construction industry. Therefore, this essential business process is relatively rarely described in connection with the ongoing digital transformation and with the use of BIM models. Many may argue that software supporting procurement processes are available. However, it is important to point out that existing software does not provide adequate functions to carry out procurement processes according to the current technological possibilities. That is why the author started to conduct research into this field and systematically advanced into a phase, where UML diagrams were modelled and published to describe the needs of procurement managers and their use cases related to procurement processes. A list of procurement managers' needs was created based on semi-structured qualitative interviews with procurement managers. Research in existing software was carried out to identify the existing software supporting procurement processes. Based on the procurement managers' needs a questionnaire was created and sent to representatives of identified software, the questionnaire was then quantitatively evaluated. Based on already published UML use case diagrams in preceding papers, new UML diagrams describing the procurement processes of subcontractors during the execution phase of a construction project are presented in the paper. It was verified that UML diagrams are a suitable instrument for modelling the procurement processes, thus research into this field will continue.
\end{abstract}

Keywords: BIM, digital transformation, procurement, UML.

\section{Introduction}

H. Lorentz explains that internal complexity dominantly drives procurement digitalisation, motivating communication support, and process structuring interventions, which in turn aim at procurement coordination and control, as well as process improvement [1]. D. Forgues and L. Koskela declare that traditional procurement processes reinforce socio-cognitive barriers that hinder team efficiency. On the contrary, they state that new procurement modes can transform the dynamic of relationships between the client and the members of the supply chain and have a positive impact on team performance [2]. A. Afolabi points out that his study showed the significant grey areas of procurement processes that need digitalization using e-procurement technologies to eradicate corrupt behaviour/tendencies [3]. The above-mentioned publications support the digitalization and innovation of procurement processes based on various reasons. M. Ajam highlights that advancements in the ICT utilisation in construction industry were unable to develop a system that exchanges/shares project information at the element level. Hence, he developed an augmented process model, which enables integrated databases to support collaborative extranets at the Tender stage [4]. E. O. Ibem and S. Laryea state that despite the progress made in the evolution and use of digital technologies in construction, there is still no single digital technology, which integrates all six construction procurement activities, defined by ISO 10845, into a system that procurers can adopt to manage the entire construction procurement lifecycle [5]. Both publications proclaim that already existing IT systems are not sufficient for covering the whole construction procurement lifecycle and propose to address this topic.

The construction project lifecycle can be divided into four general phases that can be further divided into several stages. These four phases are design, execution, operation, and disposal [6]. The author's preceding papers were focused on the design phase [7;8]. This paper focuses on the execution phase, specifically on its procurement stage, during which the procurement of subcontractors takes place. The utilized business model is the Design-Build [9]. The author's future aim is to propose a system, which will enable general contractors to process their procurement processes of subcontractors during the procurement stage transparently and seamlessly in a semi-automatic way. That is why the author started to work on possible future innovations of these processes and published his preceding research papers $[7 ; 8 ; 10]$. Project stakeholders during the procurement stage can be divided into two groups. The first group consists of project stakeholders that are already contractual partners of the project and are therefore users of the proposed system. The second group consists of project stakeholders that are 
bidding in the procurement processes and are therefore not users of the proposed system. That is why the procurement stage can be further divided into two substages for the second group of the project stakeholders. The first substage is when they are competing for the project and are not yet users of the proposed system. The second substage is when they were awarded a contract and are users of the proposed system. Hence, the proposed system needs to have adequate functions to support both substages.

The aim of the paper is to present and describe actors, their relationships, and their use cases throughout the procurement stage of an execution phase by modelling UML use case diagrams. The challenge that the author is trying to tackle is to avoid storing correspondence with bidders and tender documentation in separated IT systems. That is why functions of the proposed system are designed in a way to minimize the need for storing these data and information in separated IT systems.

The paper utilizes the Unified Modelling Language (UML) for presenting its outcomes, which is a standard visual modelling language and is a common language used to describe, specify, design, and document existing or new business processes. The UML model consists of three major categories of model elements. These categories are classifier, events, and behaviours. An actor is a classifier that specifies a role played by an external entity that interacts with the system. Use cases allow to capture requirements of systems under design or consideration, describe functionality provided by these systems and determine the requirements the systems pose on their environment. Actors, their relationships and their use cases are presented in UML use case diagrams. Use case diagrams are usually referred to as behaviour diagrams used to describe a set of actions that some system or systems should or can perform in collaboration with one or more external users of the system (actors) [11].

\section{Materials and methods}

At first, semi-structured qualitative interviews were carried out with procurement managers. The outcome of these interviews was a list of procurement manager's requirements, identification of current procurement processes, and a list of currently used IT systems. Then an analysis of identified current procurement processes of subcontractors was conducted. The outcome of this analysis was a process map presenting current processes related to the procurement of subcontractors during the design phase [7]. A list of procurement manager's requirements served as a basis for a questionnaire that was sent to representatives of existing IT systems that support procurement processes. Before the questionnaires could be sent, research of existing IT systems was carried out to identify the IT systems that support procurement processes. Then the questionnaire was sent to representatives of existing IT systems and semi-structured qualitative interviews were carried out with selected representatives. The outcome of the questionnaires and the interviews was published by the author [10].

To model UML diagrams representing relationships between actors and their use cases the author utilized his innovation and conducted research of UML diagrams. The outcome of these methods was UML diagrams of actors' relationships and their use cases during the design phase, when general contractors are sending requests for quotation to subcontractors to work out an appropriate bid for the client. This paper is also based on the author's innovation and research, and modelling of UML diagrams.

\section{Results and discussion}

This paper focuses on the procurement processes of subcontractors during the execution phase, specifically during its procurement stage. At first the system's ownership will be discussed, then the modelled UML use case diagrams will be presented and described.

\section{System's ownership}

It is considered that the owner of the proposed system during the execution phase is the general contractor, as he is responsible for the procurement processes of subcontractors, as well as for the design and the construction of the project, if the Design-Build business model is applied. This means that the general contractor is the administrator of the proposed system. However, the system could be as well owned by the client or the general designer, depending on the applied business model (e.g., Design-BidBuild). 


\section{Actors}

In terms of UML, actors are a classifier. The classifier is a UML element that has attributes and operations. An actor could be a human being, an organization, or an internal or external application that interacts with the proposed system [11].

The author identified two types of actors. The first type of actors is human beings that are represented by project stakeholders. The second type of actors is a User, who is an internal part of the system. Relationships between all identified actors are presented in Fig. 1. Several project stakeholders inherit use cases from the User, this is known as a generalization in UML [11]. Thus, they are considered as users of the proposed system. However, sub-subcontractors do not inherit use cases from the User and are hence not considered users of the proposed system. Subcontractors do inherit use cases from the User only when they are awarded a contract. That is why during the procurement process they are not considered as users of the proposed system.

The actors represented by human beings are:

- Client - abbreviation CL,

- General contractor - abbreviation GC,

- General designer - abbreviation GD,

- Subcontractor - abbreviation SUB,

- Sub-subcontractor - abbreviation SUB-SUB.

The actor represented by an internal part of the proposed system is:

- User.

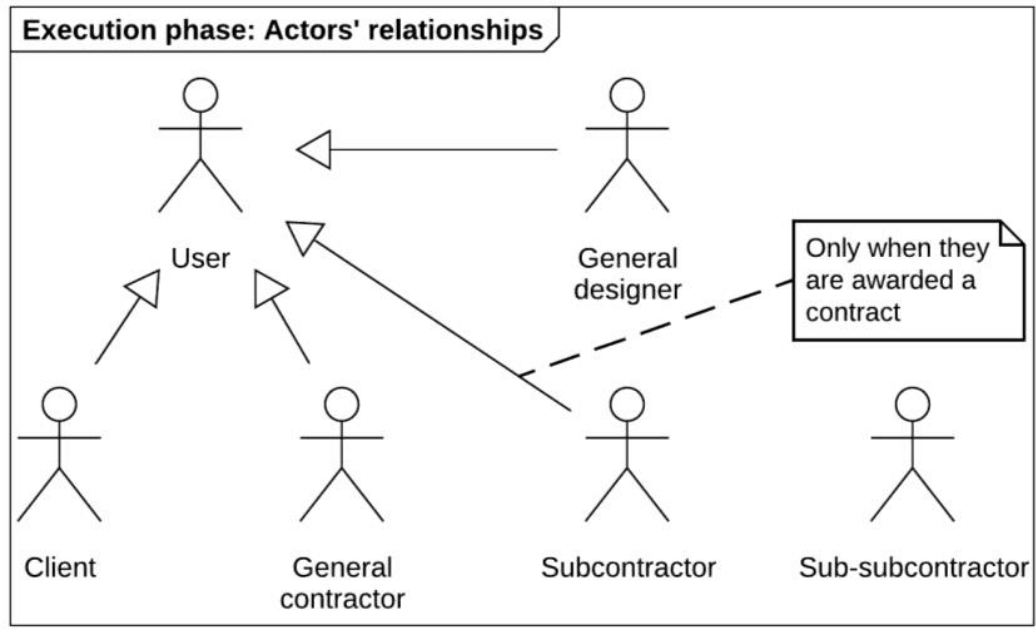

Fig. 1. Relationship between actors

\section{Use cases}

A use case is a specification of behaviour. Use cases are a means to capture the requirements of systems, i.e., what systems are supposed to do. Each use case's subject represents a system under consideration to which the use case applies. Each use case specifies some behaviour that a subject can perform in collaboration with one or more Actors. Users and any other systems that may interact with a subject are represented as Actors [11].

Use cases of all identified actors were modelled by UML use case diagrams. However, this paper presents only use case diagrams of the User and of the GC, as processes of the GC are the focus of the paper. Since the GC inherits use cases from the User, it was necessary to present his use cases as well.

\subsection{User's use cases}

The user is an internal part of the proposed system, who grants his child actors that inherit his use cases access and permissions to the proposed system. User's use cases generally enable actors that inherit them to register and login to the proposed system, reset passwords, if needed, and manage 
personal login and contact details that are stored within the proposed system. User's use cases are presented in Fig. 2.

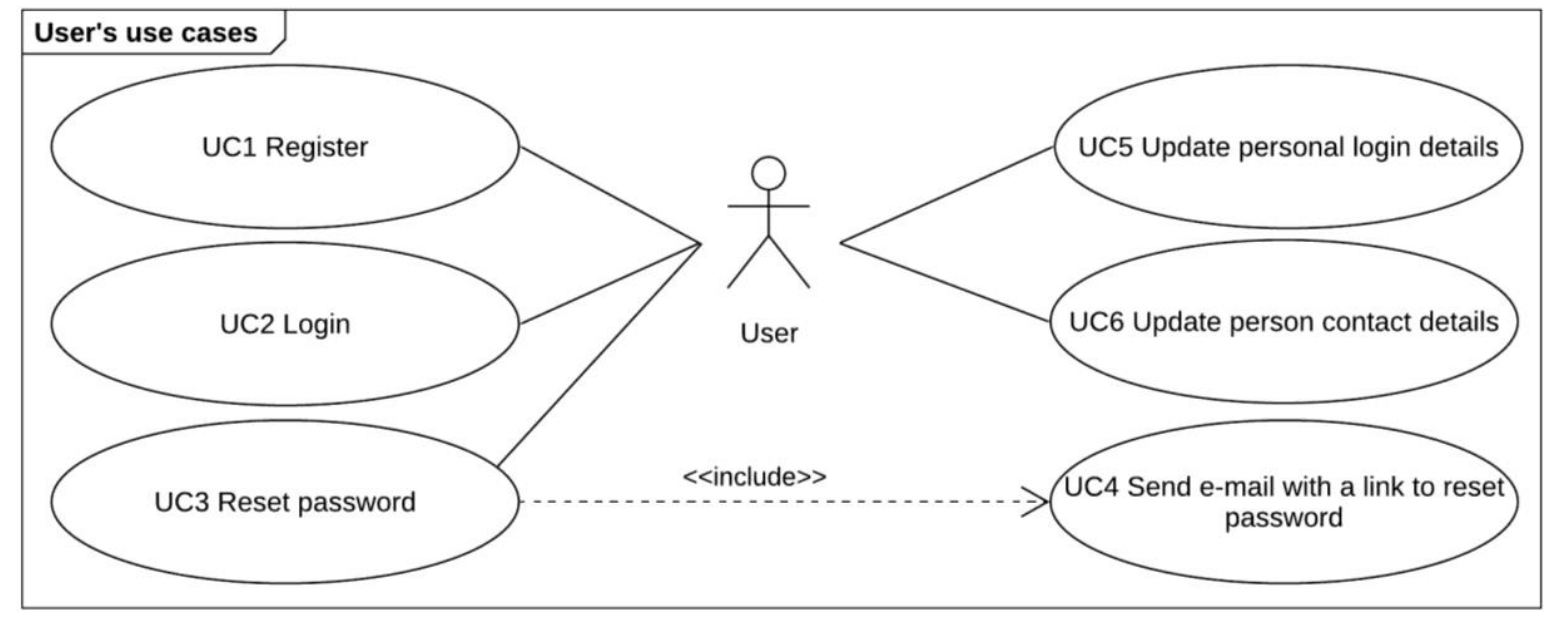

Fig. 2. User use cases

\subsection{General contractor's use cases}

GC's use cases were divided into four use case diagrams that represent various steps during the procurement stage of SUBS. These steps are project management, tender preparation, tender management, and awarding a contract. The generalization relationship between the User and the GC is not displayed in the use case diagrams intentionally, because all relationships between identified actors are presented in Fig. 1.

\section{Project management}

GC's use cases related to the project management enable the GC to create and manage a project within the proposed system and to execute general operations such as grant access and permissions to other project stakeholders, upload and approve design documentation, communicate with other users within the system and create and manage a database of SUBS. All identified use cases related to the project management step are presented in Fig. 3.

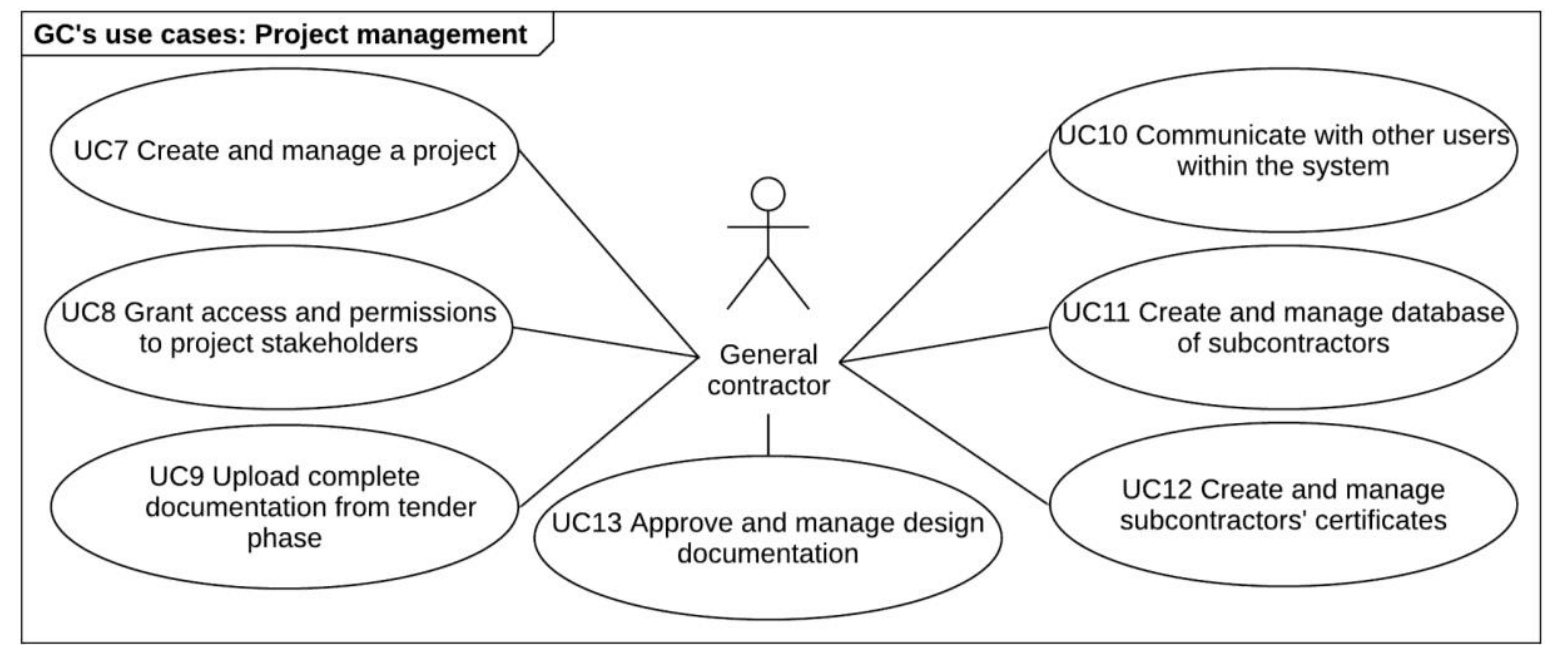

Fig. 3. General contractor use cases - Project management

\section{Tender preparation}

GC's use cases related to the tender preparation support the GC during the preparation of work packages that will need to be procured and are presented in Fig. 4. Work package (WP) is a category of construction works or materials that will need to be executed or delivered onto the construction site (e.g., concrete works, waterproofing material, etc.). 


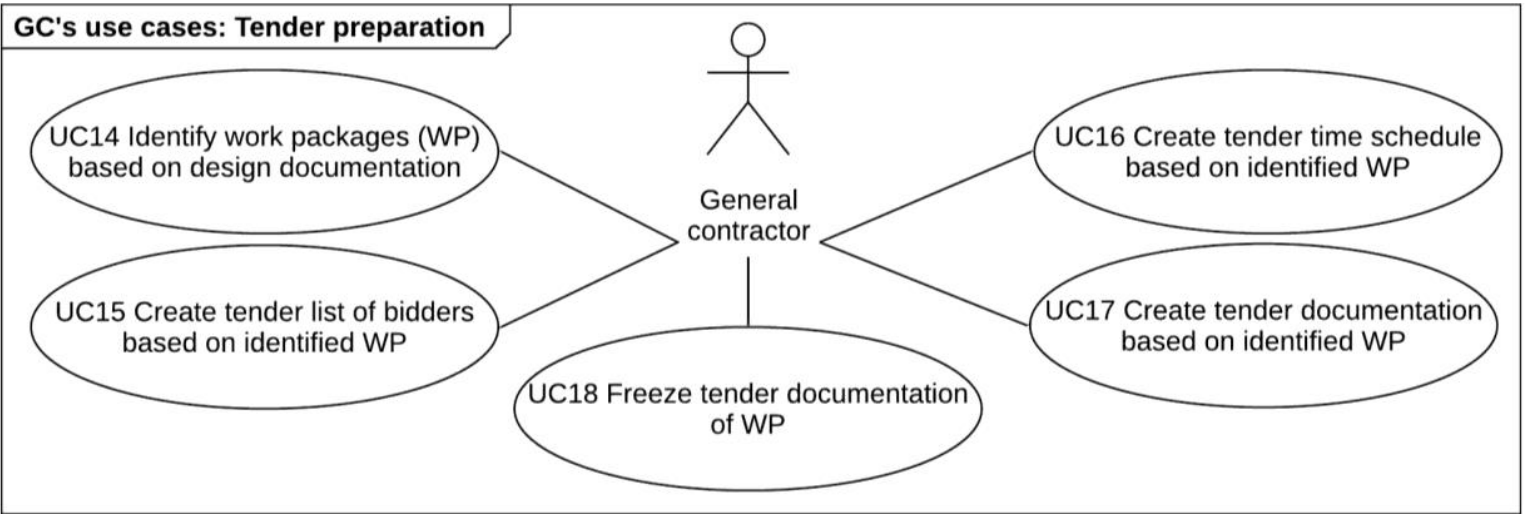

Fig. 4. General contractor use cases - Tender preparation

The system shall semi-automatically propose appropriate work packages based on design documentation and/or BIM models, as well as semi-automatically create a tender list of bidders and a tender time schedule, and tender documentation based on identified work packages. Created tender documentation corresponding to identified work packages shall be frozen to be made static. This will ensure that all inquired bidders will work out their bids based on the same tender documentation, because the source design documentation may change during the execution phase of a project. The tender documentation of work packages is linked with the source design documentation, not copied to prevent duplicating the files.

\section{Tender management}

GC's use cases related to the tender management support the GC throughout the management of tenders of identified work packages and are presented in Fig. 5. During this step, the work packages are being inquired. That is why, the correspondence with bidders will be managed with the use of templates of correspondence (e.g., the template of request for proposal, etc.).

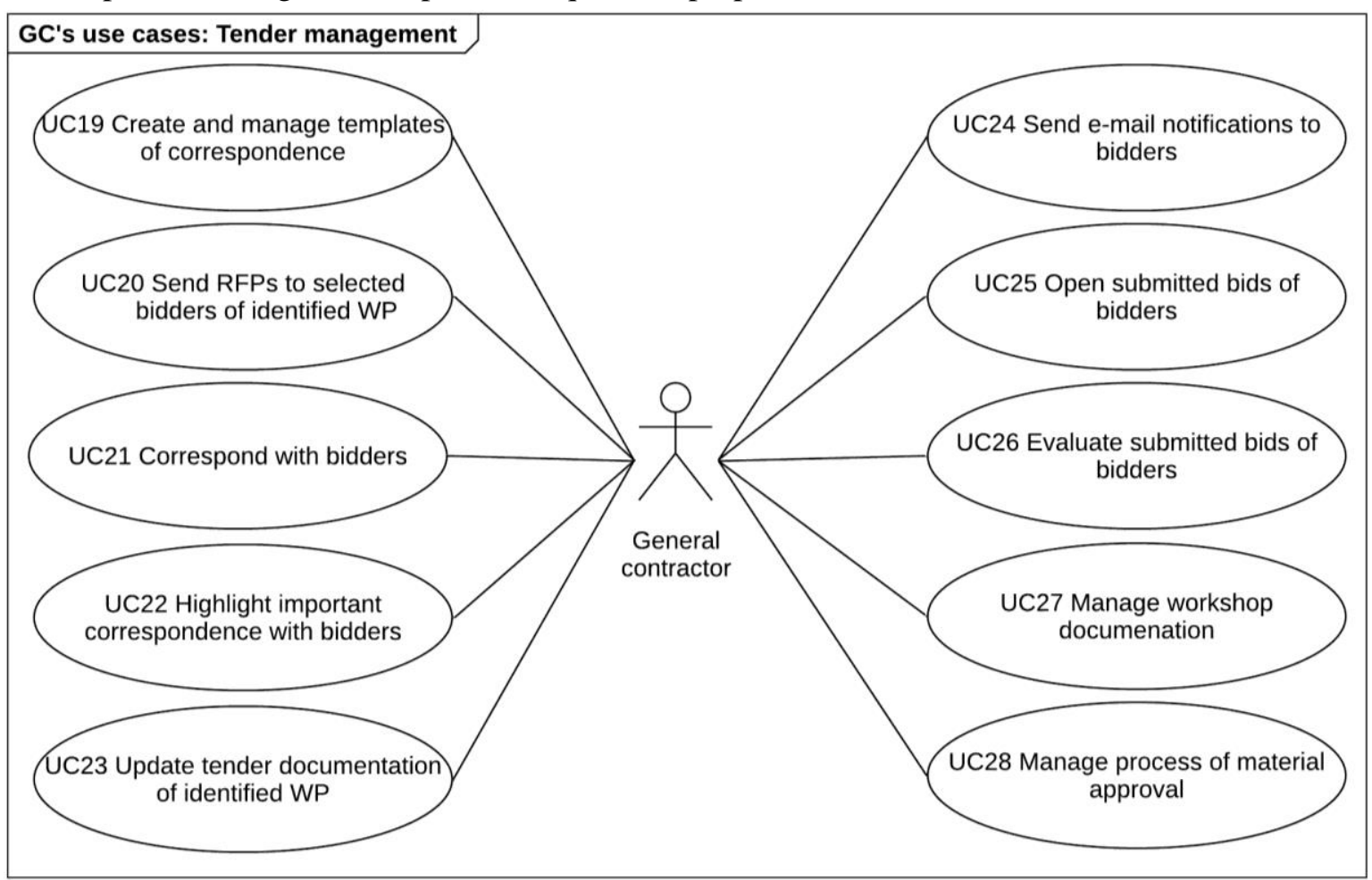

Fig. 5. General contractor use cases - Tender management

Important correspondence will be semi-automatically highlighted by the system based on the received e-mail's content, however, the user's activity will be required to evaluate if it was highlighted correctly. Highlighted important correspondence will be recorded and monitored in the tender time 
schedule. If the source design documentation is updated, then shall the GC manually update the statically linked tender documentation by the system's designated function. Simultaneously shall the system inform the inquired bidders of work packages about the update of the corresponding tender documentation. Bidders shall be able to submit their bids into the system, hence the GC can open and evaluate them, however, their detailed evaluation does not have to occur in the proposed system. A detailed description of the selection methods of SUBS is not provided because it can vary by project. As the CL or the GD might like to approve the bidders' workshop documentation and/or proposed materials, it shall be also possible to manage related processes.

\section{Awarding a contract}

GC's use cases related to the awarding of a contract are presented in Fig. 6. During this step awarded SUB's workers are granted access and permissions to the proposed system, hence become users of the proposed system. The GC has to generate a contract for work for the selected SUBS using templates of contracts, which will be automatically filled in with values from the proposed system. The GC will manage templates of contracts in a way that contract types that he utilizes on his project are available in the proposed system. At the same time, tender documentation of awarded work packages shall be made dynamic for the selected SUBS. This will ensure that they have always updated approved design documentation at their disposal. At a predefined moment shall the GC evaluate the overall cooperation with inquired bidders and selected SUBS and score them within the database of SUBS.

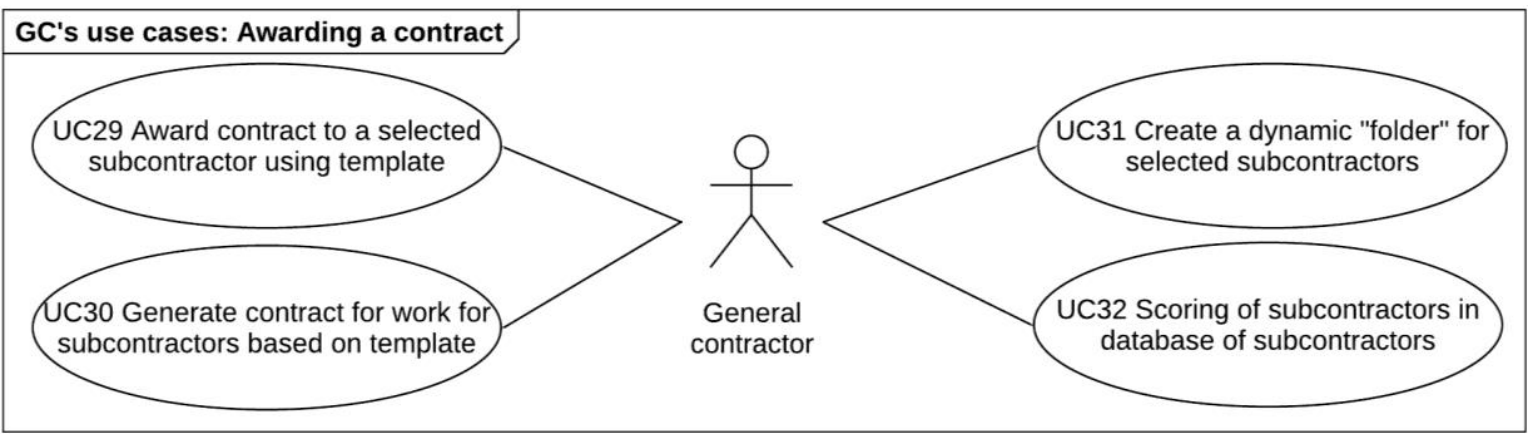

Fig. 6. General contractor use cases - Awarding a contract

Tenders of work packages are closed when a bidder is awarded a contract. Tenders of work packages where no bidder had been awarded a contract are being processed or waiting for processing.

\section{Conclusions}

The aim of the paper was accomplished. Actors, their relationships, and their use cases throughout the procurement stage of an execution phase were modelled by UML use case diagrams and presented in the paper.

1. Two types of actors were identified. The first type is real human beings and the second type is a user, who is an internal part of the proposed system.

2. Relationships between identified actors were modelled by the UML use case diagrams and a generalization between the User and other project stakeholders was presented and described.

3. User's use cases were presented by the UML use case diagram and described.

4. General contractor's use cases were divided into four steps during the procurement stage of SUBS. All GC's use cases were modelled by the UML use case diagrams and described.

\section{Acknowledgements}

This work was supported by the Grant Agency of the Czech Technical University in Prague, grant No. SGS20/101/OHK1/2T/11.

\section{References}

[1] Lorentz H., Aminoff A., Kaipia R., and Srai J. S. Structuring the phenomenon of procurement digitalisation: contexts, interventions and mechanisms, International Journal of Operations \& Production Management, vol. 41, no. 2, 2021, pp. 157-192. 
[2] Forgues D. and Koskela L. The influence of a collaborative procurement approach using integrated design in construction on project team performance. International Journal of Managing Projects in Business, vol. 2, no. 3, 2009, pp. 370-385.

[3] Afolabi A., Ibem E., Aduwo E., and Tunji-Olayeni P. Digitizing the grey areas in the Nigerian public procurement system using e-Procurement technologies. International Journal of Construction Management, vol. 0, no. 0, 2020, pp. 1-10.

[4] Ajam M., Alshawi M., and Mezher T. Augmented process model for e-tendering: Towards integrating object models with document management systems. Automation in Construction, vol. 19, no. 6, 2010, pp. 762-778.

[5] Ibem E. O. and Laryea S. Survey of digital technologies in procurement of construction projects. Automation in Construction, vol. 46, 2014, pp. 11-21.

[6] Life cycle in the built environment, "Designing Buildings Ltd.". [online] [27.10.2020]. Available at: https://www.designingbuildings.co.uk/wiki/Life_cycle_in_the_built_environment

[7] Stránský M., Matějka P., Kupec J. Process map of current tender processes of subcontractors. Business \& IT, vol. IX, no. 2, 2019, pp. 53-61.

[8] Stránský M. Utilization of UML Modeling in Construction Procurement. Proceedings of conference "Construction Maeconomics Conference", Oct. 22, 2020, Prague, Czech Republic.

[9] Gransberg D. D., Koch J. E., and Molennar K. R., Preparing for Design-Build Projects, vol. 2006. Reston: American Society of Civil Engineers, 2006. 279 p.

[10] Stránský M. Functions of Common Data Environment Supporting Procurement of Subcontractors. Proceedings of International conference "Engineering for rural development 2020", May 20-22, 2020, Jelgava, Latvia, pp. 793-799.

[11] The Unified Modeling Language version 2.5.1 "Object Management Group". [online] [12.2017]. Available at: https://www.omg.org/spec/UML/About-UML/. 